\title{
Use of scalp hair as indicator of human exposure to heavy metals in an electronic waste recycling area
}

\author{
Thanh Wang ${ }^{a}$, Jianjie $\mathrm{Fu}^{\mathrm{a}}$, Yawei Wang ${ }^{\mathrm{a}}$, Chunyang Liao ${ }^{\mathrm{a}}$, Yongqing Tao ${ }^{\mathrm{b}}$, Guibin Jiang ${ }^{\mathrm{a}, *}$ \\ ${ }^{a}$ State Key Laboratory of Environmental Chemistry and Ecotoxicology, Research Center for Eco-Environmental Sciences, Chinese Academy of Sciences, 18 Shuangqing Road, \\ Haidian District, P.O. Box 2871, Beijing 100085, China \\ b Shangyu Environmental Protection Bureau, 312300 Shaoxing, Zhejiang, China \\ Human scalp hair samples can be used to indicate environmental and occupational exposure of heavy metals due to intensive electronic waste \\ recycling activities.
}

\section{A R T I C L E I N F O}

\section{Article history:}

Received 23 December 2008

Received in revised form

3 March 2009

Accepted 7 March 2009

\section{Keywords:}

Hair

Biomarker

Electronic waste recycling

Human exposure

Multivariate analysis

Heavy metals

Trace elements

\begin{abstract}
A B S T R A C T
Scalp hair samples were collected at an electronic waste (e-waste) recycling area and analyzed for trace elements and heavy metals. Elevated levels were found for $\mathrm{Cu}$ and $\mathrm{Pb}$ with geometric means (GMs) at 39.8 and $49.5 \mu \mathrm{g} / \mathrm{g}$, and the levels of all elements were found in the rank order $\mathrm{Pb}>\mathrm{Cu} \gg \mathrm{Mn}>\mathrm{Ba}>\mathrm{Cr}>\mathrm{Ni}>\mathrm{Cd}>\mathrm{As}>\mathrm{V}$. Besides $\mathrm{Cu}$ and $\mathrm{Pb}, \mathrm{Cd}$ (GM: $0.518 \mu \mathrm{g} / \mathrm{g}$ ) was also found to be significantly higher compared to that in hair samples from control areas. Differences with age, gender, residence status and villages could be distinguished for most of the elements. The high levels of $\mathrm{Cd}, \mathrm{Cu}$ and $\mathrm{Pb}$ were likely found to be originated from e-waste related activities, and specific sources were discussed. This study shows that human scalp hair could be a useful biomarker to assess the extent of heavy metal exposure to workers and residents in areas with intensive e-waste recycling activities.
\end{abstract}

(c) 2009 Elsevier Ltd. All rights reserved.

\section{Introduction}

The increased demand and production of electronic products in the past decades have created problems in regards to the whereabouts of the rising number of waste electrical and electronic equipments (e-waste). Although a significant proportion of obsolete electronic waste eventually winds up in landfills and municipal waste incinerators, there is a growing number that ends up in recycling facilities in order to recover reusable and recyclable materials and trace amounts of precious metals. However, since most industrialized countries have strict domestic regulations involving the safe handling of e-wastes and the labor intensiveness of manual disassembly processes, recycling of e-waste within these countries is usually not very economically feasible. Although most countries have ratified the Basel Convention, which strictly controls the transboundary movements of hazardous wastes (including e-wastes), unregulated and even illegal export of e-waste still takes place to transition or developing countries such as China, India and Nigeria (United Nations Environment Programme, 2005). In these

\footnotetext{
* Corresponding author. Tel.: +8610 6284 9179; fax: +8610 62849334

E-mail address: gbjiang@rcees.ac.cn (G. Jiang).
}

countries, rudimentary processes such as open burning and acid stripping, which are common practices to recover valuable compounds in e-waste, often result in the release of high levels of organic pollutants such as polycyclic aromatic hydrocarbons (PAHs), polychlorinated dibenzo-p-dioxins and furans (PCDD/Fs), polychlorinated biphenyls (PCBs), polybrominated diphenyl ethers (PBDEs), and toxic heavy metals such as $\mathrm{Pb}, \mathrm{Cd}, \mathrm{Cr}$, and $\mathrm{Cu}$ (Basel Action Network, 2002; Deng et al., 2006; Gullett et al., 2007; Leung et al., 2007; Li et al., 2007). Besides obvious health implications for the dismantling workers, the pollutants can also contaminate the surrounding environment and further be transported to other areas adjacent to the recycling centers, such as rice fields (Fu et al., 2008), soils (Leung et al., 2006), and rivers and sediment (Wong et al., 2007b). Studies on the potential occupational and environmental exposures and subsequent human health implications of these recycling activities are still inadequate and therefore important.

Human scalp hair has been used as an alternative biological material for blood and urine in biomonitoring environmental and occupational exposures of various pollutants, since its sampling is considered less invasive, more convenient to store and transport, and less hazardous to handle. Furthermore, hair sample can be a useful assessment tool as the measured contaminant levels can reflect exposure from a long-term period (weeks to years depending 
on hair length) and certain elements may be present in high concentrations in hair strands. This can be compared to blood and urine which often reflect most recent exposures, and might only contain minute amounts of the chemicals of interest, making analysis a difficult challenge. Scalp hair has been used in biomonitoring of heavy metals on large cohorts (Rodrigues et al., 2008), determining occupational exposure (Morton et al., 2002) and exposure to local habitants in polluted areas (Pereira et al., 2004). Scalp hair has also been used to monitor the potential exposure of organic pollutants such as PCBs and PBDEs to inhabitants in e-waste recycling areas (Zhao et al., 2008) and dismantling workers (Wen et al., 2008). As electronic components contain high amount of certain toxic trace elements and heavy metals, such as $\mathrm{As}, \mathrm{Cd}, \mathrm{Ni}$ and $\mathrm{Pb}$, we focus our study on examining the residential exposure of selected trace elements in a well known recycling area, Taizhou in southeastern China, by analyzing scalp hair samples collected in local barber shops. To our knowledge, trace elements and heavy metals in hair have not been previously used to assess the exposure of e-waste activities, and our study is one of the very few studies on human exposure to trace elements and heavy metals in areas associated with e-waste recycling.

\section{Materials and methods}

\subsection{Sampling site description}

Taizhou is a prefecture-level region located in Zhejiang province in southeastern China. E-waste recycling has been ongoing in this area for almost two decades, with majority of the dismantling and recovery processes usually being carried out in small family owned workshops in rural villages where most of the residents are directly or indirectly involved in e-waste related activities. In attempting to manage the unregulated e-waste processing, the local administration in Taizhou has also established several e-waste recycling industry parks, where enterprises are processing e-waste in a more environmental regulated and controlled manner, such as the adoption of waste treatments (Hicks et al., 2005). Ningbo (NB) and Shaoxing (SX), two industrialized cities situated in the same province about $130 \mathrm{~km}$ north and 160 northwest of Taizhou, respectively, were used as control areas. This would allow for, to some extent, comparison between exposure to general industrial activities and those deriving from e-waste recycling activities.

\subsection{Sample collection}

Scalp hair samples were collected from the volunteer participants using stainless steel scissors during their routine haircut sessions in barber shops near e-waste workshops in the villages; Baifengqiao (BFQ $28^{\circ} 32^{\prime} \mathrm{N}, 121^{\circ} 22^{\prime} \mathrm{E}$ ), Anrong (AN, $28^{\circ} 31^{\prime} \mathrm{N}, 121^{\circ} 20^{\prime} \mathrm{E}$ ), Baifeng'ao (BFA, $28^{\circ} 32^{\prime} \mathrm{N}, 121^{\circ} 21^{\prime} \mathrm{E}$ ), Xiatao (XT, $28^{\circ} 32^{\prime} \mathrm{N}$, $\left.121^{\circ} 23^{\prime} \mathrm{E}\right)$ and an e-waste recycling park ( $\left.\mathrm{RP}, 28^{\circ} 31^{\prime} \mathrm{N}, 121^{\circ} 22^{\prime} \mathrm{E}\right)$ around the Taizhou (TZ) area during 2007-2008. All study participants gave their consent for our study; permission was obtained from parents of children for their participation. Information regarding age, gender and residence status (local permanent residents or nonlocal migrants) was collected. As most of the participants had short $(<10 \mathrm{~cm})$ to medium $(10-20 \mathrm{~cm})$ hair length, their hair was collected from all around the scalp, whereas only the proximal part to the scalp was collected for those few with long hair $(>20 \mathrm{~cm}$ ). No information was collected regarding hair treatments, dyeing or washing routines but those few samples which by visual examination indicated dyeing/bleaching (since these treatments would result in hair colors/tones other than natural black) was excluded. Each sample was stored in a plastic bag together with the collected questionnaire for each individual, and shipped to our laboratory for analysis. A total of 139 samples were obtained from Taizhou and ten samples from each of the control sites, Ningbo and Shaoxing.

\subsection{Sample pre-treatment}

The hair sample was cut into smaller pieces, thoroughly mixed, and an ample proportion were washed using the method described by Altshul et al. (2004), with some modifications. In short, $50 \mathrm{~mL}$ of hot deionized water was added to the hair sample and sonicated for $30 \mathrm{~min}$, and thereafter washed again three times with deionized water. The hair sample was then placed in a $50 \mathrm{~mL}$ polyethylene terephthalate (PET) screw-cap vial filled with $30 \mathrm{~mL}$ deionized water, and one drop of a mild commercial shampoo (Soft and Shiny Baby Shampoo, Johnson \& Johnson ${ }^{\circledR}$, Shanghai, China) was added and the solution was shaken for $5 \mathrm{~min}$. The sample was thereafter rinsed five times with $30 \mathrm{~mL}$ deionized water each rinse. Then another drop of the shampoo was added, the vial mechanically shaken for $30 \mathrm{~min}$, and again washed five times with water. After decanting the solution, the samples were freeze dried under vacuum.

After drying, the samples were ground to powder by using liquid nitrogen and mortar and pestle. The powdered samples were then freeze dried under vacuum again and stored in PET bottles. For digestion, $0.1 \mathrm{~g}$ of the sample was transferred into a Teflon ${ }^{\circledR}$ digestion vessel and $2 \mathrm{~mL}$ concentrated nitric acid $(69 \%$, analytical grade, Sigma-Aldrich) was added and left to predigest for $30 \mathrm{~min}$. Afterwards, $1 \mathrm{~mL}$ of $30 \%$ hydrogen peroxide (granted reagent, Beijing Chemical Company) was added and the vessels were transferred to a microwave digestion unit (CEM Mars-X 500, USA). The digestion program was as follows: ramp to $160{ }^{\circ} \mathrm{C}$ in $10 \mathrm{~min}, 160{ }^{\circ} \mathrm{C}$ for $30 \mathrm{~min}$, ramp $160-180^{\circ} \mathrm{C}$ in $10 \mathrm{~min}$, and hold at $180^{\circ} \mathrm{C}$ for $30 \mathrm{~min}$. After cooling to room temperature, the digest was diluted to $25 \mathrm{~mL}$ with Milli-Q water (Millipore, Bedford, MA), and ready for analysis.

\subsection{Instrumental analysis}

The samples were analyzed with an inductively coupled plasma mass spectrometer (ICP-MS, Agilent 7500ce), for total concentrations of $\mathrm{As}, \mathrm{Ba}, \mathrm{Cd}, \mathrm{Cr}, \mathrm{Cu}, \mathrm{Mn}$, $\mathrm{Ni}, \mathrm{Pb}$, and $\mathrm{V}$. All the determinations were performed in triplicate using the external standard calibration method, and with yttrium as internal standard.

\subsection{Quality assurance and quality control}

Pilot studies showed that measured elements in the shampoo were found at low ppb levels, and the shampoo washing step showed comparable or slightly better removal efficiency of exogenous elements than the International Atomic Energy Agency (IAEA) method $(3 \times 30 \mathrm{~mL}$ water, $3 \times 30 \mathrm{~mL}$ acetone, $3 \times 30 \mathrm{~mL}$ water), corroborating with a previous study which showed that washing with commercial shampoo provided comparable performance as other washing methods (Morton et al., 2002). The washing procedure was validated to assure that loosely bound exogenous contamination has been properly removed by comparing with unwashed hair samples and analyzing the last washing solution, which showed comparable levels for the selected elements as procedural blank samples. The method limits of detection for the selected trace elements were calculated as three times the standard deviation for digestion blanks ( $n=5$ ) and were; (As) $0.075 \mathrm{ng} / \mathrm{g}$, (Ba) $0.336 \mathrm{ng} / \mathrm{g}$, (Cd) $0.011 \mathrm{ng} / \mathrm{g},(\mathrm{Cr}) 0.278 \mathrm{ng} / \mathrm{g}$, (Cu) $0.213 \mathrm{ng} / \mathrm{g}$, (Mn) $0.218 \mathrm{ng} / \mathrm{g}$, (Ni) $0.230 \mathrm{ng} / \mathrm{g}$, (Pb) $0.251 \mathrm{ng} / \mathrm{g}$, (V) $0.058 \mathrm{ng} / \mathrm{g}$. Triplicate injections into the ICP-MS showed very good reproducibility and in general $<2 \%$. Standard solution was checked for every 10 samples and the results agreed within $\pm 10 \%$ of the original value. Due to the unavailability of appropriate and reliable certified hair standards for the validation of our method, standard addition method was performed with several samples, which were spiked with standards and subjected to the same digestion and analysis procedures. Satisfactory recoveries were obtained for the elements (70-99\%), and procedural replicates showed RSD $<10 \%$ for all analyzed elements $(n=7)$.

\subsection{Statistical analysis}

Data analysis was performed using SPSS for Windows Release 13.0 (SPSS Inc.) Normality tests showed nonparametric distributions and the data were, when appropriate, log-transformed prior to standard statistical parametric tests, Pearson's correlation and principal component analysis (PCA). Geometric means (GMs) were used throughout the manuscript and the level of statistical significance was set at $p<0.05$, unless otherwise mentioned.

\section{Results and discussion}

The GMs for the elements in Taizhou (TZ) were the rank order of $\mathrm{Pb}>\mathrm{Cu} \gg \mathrm{Mn}>\mathrm{Ba}>\mathrm{Cr}>\mathrm{Ni}>\mathrm{Cd}>\mathrm{As}>\mathrm{V}$. These were higher than the control areas, Ningbo (NB) and Shaoxing (SX) except for As and $\mathrm{V}$, although statistically significant only for $\mathrm{Cd}(\mathrm{GM}=0.518 \mu \mathrm{g} /$ g), $\mathrm{Cu}(39.8 \mu \mathrm{g} / \mathrm{g}), \mathrm{Mn}(5.32 \mu \mathrm{g} / \mathrm{g})$, and $\mathrm{Pb}(49.5 \mu \mathrm{g} / \mathrm{g}),(p<0.05$; Table 1$)$. The levels from the control areas were comparable with or even higher than those published in previous studies on urban populations (Rodushkin and Axelsson, 2000; Chojnacka et al., 2005). Some subjects in $\mathrm{TZ}$ on the other hand, showed extremely high levels of $\mathrm{Cu}$ and $\mathrm{Pb}$, with the 95th percentile estimate at 143 and $251 \mu \mathrm{g} / \mathrm{g}$, respectively. The concentrations for the control groups were found only to be in the range $5.27-14.0 \mu \mathrm{g} / \mathrm{g}$ for $\mathrm{Cu}$ and 1.09-15.9 $\mu \mathrm{g} / \mathrm{g}$ for $\mathrm{Pb}$ (Table 1 ), and the GMs were much lower than those in TZ (Fig. 1). All elements were found at higher levels than those of non-occupationally exposed populations in Sweden and France, with some elements such as Cd showing around 20 times higher (median $0.552 \mu \mathrm{g} / \mathrm{g}$ ) and $\mathrm{Pb}(53.1 \mu \mathrm{g} / \mathrm{g})$ showing 80 times higher levels (Supplementary Material, Table S1). Furthermore, the 
Table 1

Levels of trace elements in samples from Taizhou, Ningbo and Shaoxing.

\begin{tabular}{|c|c|c|c|c|c|c|}
\hline \multirow[t]{3}{*}{ Element } & \multicolumn{2}{|l|}{ Taizhou } & \multicolumn{2}{|l|}{ Ningbo } & \multicolumn{2}{|l|}{ Shaoxing } \\
\hline & $\mathrm{AM} \pm \mathrm{STD}$ & Range (median) & $\mathrm{AM} \pm \mathrm{STD}$ & Range (median) & $\mathrm{AM} \pm \mathrm{STD}$ & Range (median) \\
\hline & GM (GSD) & & GM (GSD) & & GM (GSD) & \\
\hline$\overline{\text { As }}$ & $\begin{array}{l}0.423 \pm 0.384 \\
0.328(1.94)\end{array}$ & $0.0879-2.21(0.295)$ & $\begin{array}{l}0.282 \pm 0.0347 \\
0.265(1.17)\end{array}$ & $0.212-0.340(0.265)$ & $\begin{array}{l}0.585 \pm 0.220 \\
0.556(1.43)\end{array}$ & $0.373-1.08(0.534)$ \\
\hline $\mathrm{Ba}$ & $\begin{array}{l}3.77 \pm 4.54 \\
3.03(1.78)\end{array}$ & $0.978-50.9(2.97)$ & $\begin{array}{l}2.33 \pm 1.01 \\
2.10(1.67)\end{array}$ & $0.891-3.36(2.41)$ & $\begin{array}{l}2.09 \pm 1.50 \\
1.68(1.92)\end{array}$ & $0.635-4.59(1.41)$ \\
\hline $\mathrm{Cd}$ & $\begin{array}{l}0.940 \pm 1.40 \\
0.518(3.11)\end{array}$ & $0.0100-13.7(0.552)$ & $\begin{array}{l}0.209 \pm 0.0340 \\
0.225(1.26)\end{array}$ & $0.175-0.325(0.217)$ & $\begin{array}{l}0.223 \pm 0.0814 \\
0.210(1.38)\end{array}$ & $0.123-0.338(0.190)$ \\
\hline $\mathrm{Cr}$ & $\begin{array}{l}1.591 \pm 1.16 \\
1.32(1.80)\end{array}$ & $0.406-7.15(1.14)$ & $\begin{array}{l}1.16 \pm 0.731 \\
1.02(1.61)\end{array}$ & $0.677-2.52(0.932)$ & $\begin{array}{l}1.15 \pm 0.240 \\
1.13(1.21)\end{array}$ & $0.892-1.66(1.08)$ \\
\hline $\mathrm{Cu}$ & $\begin{array}{l}53.0 \pm 59.5 \\
39.8(1.94)\end{array}$ & $10.85-537(38.4)$ & $\begin{array}{l}10.7 \pm 1.56 \\
9.93(1.29)\end{array}$ & $5.27-14.0(10.3)$ & $\begin{array}{l}10.2 \pm 1.21 \\
10.1(1.24)\end{array}$ & $8.49-11.8(9.98)$ \\
\hline Mn & $\begin{array}{l}7.96 \pm 8.97 \\
5.32(2.32)\end{array}$ & $0.457-50.9(5.11)$ & $\begin{array}{l}1.03 \pm 0.592 \\
1.02(1.86)\end{array}$ & $0.418-3.19(0.887)$ & $\begin{array}{l}3.04 \pm 1.40 \\
2.72(2.18)\end{array}$ & $1.17-5.29(2.91)$ \\
\hline $\mathrm{Ni}$ & $\begin{array}{l}1.77 \pm 1.62 \\
1.09(2.68)\end{array}$ & $0.007-9.44(1.52)$ & $\begin{array}{l}0.812 \pm 0.447 \\
0.887(1.92)\end{array}$ & $0.369-3.01(0.850)$ & $\begin{array}{l}0.597 \pm 0.170 \\
0.577(2.70)\end{array}$ & $0.422-0.861(0.533)$ \\
\hline $\mathrm{Pb}$ & $\begin{array}{l}85.3 \pm 96.4 \\
49.5(2.93)\end{array}$ & $1.93-730(53.1)$ & $\begin{array}{l}2.98 \pm 2.77 \\
2.53(2.12)\end{array}$ & $1.09-8.77(2.18)$ & $\begin{array}{l}7.60 \pm 4.49 \\
6.61(1.70)\end{array}$ & $3.50-15.9(5.89)$ \\
\hline V & $\begin{array}{l}0.174 \pm 0.0566 \\
0.166(1.34)\end{array}$ & $0.0972-0.342(0.158)$ & $\begin{array}{l}0.226 \pm 0.0241 \\
0.223(1.10)\end{array}$ & $0.207-0.274(0.214)$ & $\begin{array}{l}0.500 \pm 0.160 \\
0.483(1.31)\end{array}$ & $0.383-0.882(0.460)$ \\
\hline
\end{tabular}

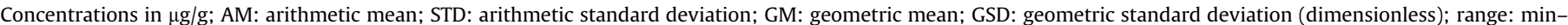
$\max$.

median level of $\mathrm{Pb}$ in $\mathrm{TZ}$ was approximately 3-10 times higher than the levels for foundry workers occupationally exposed to $\mathrm{Pb}$ (Morton et al., 2002). Khuder and co-workers (2008) analyzed hair of exposed workers in Syria using X-ray fluorescence analysis, and found extremely high concentrations of $\mathrm{Pb}$ for workers in a battery plant (median $198 \mu \mathrm{g} / \mathrm{g}$ ), but the levels of $\mathrm{Cu}$ (median $17.8 \mu \mathrm{g} / \mathrm{g}$ ) in hair of workers in a cable manufacturing plant were lower than what was found in our study. It must however be mentioned that different washing and analytical methods were used and since no standardized protocol for hair analysis currently exists, comparing results from different studies should be made with caution.

The elevated levels of $\mathrm{Cu}$ and $\mathrm{Pb}$ in $\mathrm{TZ}$ subjects could be the result of exposure from e-waste recycling activities. Copper is a main component in electric wires and cables and is mainly recovered by open burning. Lead is widely used in electric goods,

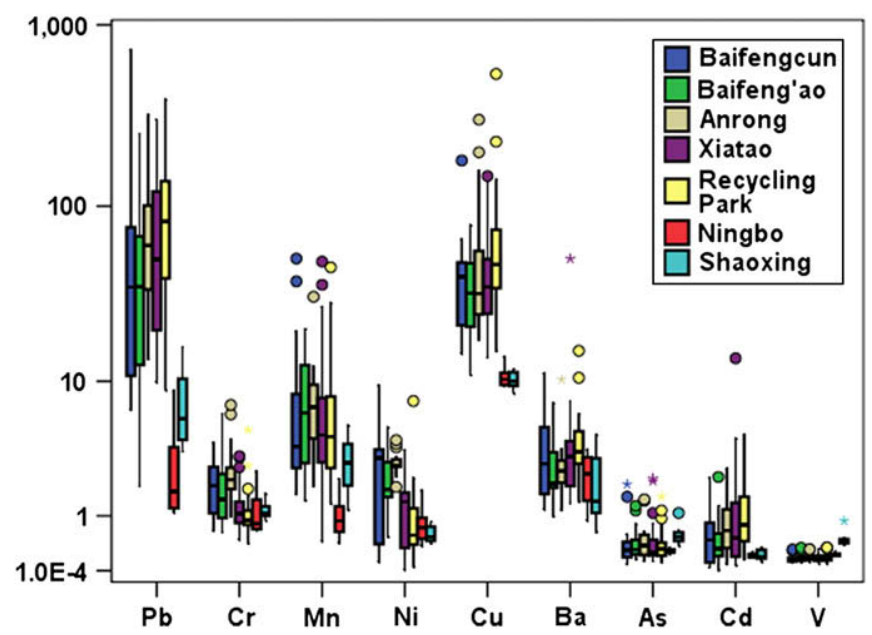

Fig. 1. Box-plot diagram of selected elements for the subjects grouped by villages in TZ; Baifengqiao $(n=20)$, Baifeng'ao $(n=24)$, Anrong $(n=20)$, Xiatao $(n=38)$, Recycling Park $(n=37)$, and the control areas; Ningbo $(n=10)$ and Shaoxing $(n=10)$. Concentrations in $\mu \mathrm{g} / \mathrm{g}, y$-axis is presented in logarithmic scale. Middle band, box and whiskers represent the median, 25 th and 75 th percentile, and 5 th and 95 th percentile, respectively. Circles represent outliers, whereas “*” represent extreme values. ranging from batteries, printed circuit boards to cathode ray tubes and as stabilizers in PVC cables, and is primarily recovered by manually de-soldering the components of e.g. printed circuit boards. Previous studies conducted in Guiyu, another notorious e-waste recycling area in Guangdong province in China, found significantly high amounts of these two metals in the local rivers and sediments (Wong et al., 2007a) and atmosphere (Deng et al., 2006). Another study found extremely elevated levels of $\mathrm{Cu}$ and $\mathrm{Pb}$ in dust samples inside workshops ( $\mathrm{Cu}: 8360 \mu \mathrm{g} / \mathrm{g}$ and $\mathrm{Pb}$ : $110,000 \mu \mathrm{g} / \mathrm{g}$ ) and roads (106 and $330 \mu \mathrm{g} / \mathrm{g}$ ) near these recycling facilities (Leung et al., 2008). Dismantling workers and residents are then at risk of being exposed to toxic levels of these metals through inhalation of fumes, ingestion of dust, and intake of contaminated food and drinking water. These concerns were further supported by the findings of significantly elevated blood lead levels in children ( $\leq$ six years old) in the same area (Huo et al., 2007). Lead and cadmium are toxic heavy metals and can also enter the body of non-occupationally exposed individuals in minute amounts through smoking, drinking water and food. Although no information could be gathered on the smoking habits of the participants, previous studies observed that non-occupationally exposed smokers had hair lead levels at lower $\mu \mathrm{g} / \mathrm{g}$ ranges (Wolfsperger et al., 1994; Rodushkin and Axelsson, 2000), which should not be sufficient to explain the high levels found in the hair samples in TZ. In addition, TZ, NB and SX are all situated close to the coast and should share similar diet; with a significant contribution of seafood. Fu et al. (2008) found that local rice grown around e-waste areas in Taizhou had elevated levels of several elements compared to commercial rice in China, and calculated that contaminated Taizhou rice would alone contribute to $67 \%$ and $103 \%$ of the tolerable daily intake for $\mathrm{Cd}$ and $\mathrm{Pb}$, respectively.

Cadmium is used in batteries, semiconductors and photoconductive surface coating for photocopier drums. It is also used as stabilizer in PVC plastics, and might therefore be present in wire cables. Taizhou subjects showed approximately twice as high levels of $\mathrm{Cd}(\mathrm{GM}=0.526 \mu \mathrm{g} / \mathrm{g})$ than the controls and that of regular smokers in northern Sweden (Rodushkin and Axelsson, 2000).

Manganese is used as an additive in gasoline and in steel production, but it also occurs naturally in e.g. surface soils and groundwater. The levels of $\mathrm{Mn}$ in hair in $\mathrm{TZ}(\mathrm{GM}=5.32$, 
median $=5.11 \mu \mathrm{g} / \mathrm{g}$ ) were about two and five times higher than those found in SX and NB, but was lower than another study in Vietnam which found a strong correlation between Mn contaminated groundwater (median $>1000 \mu \mathrm{g} / \mathrm{L}$ ) and elevated hair levels (median 8.36-18.3 $\mu \mathrm{g} / \mathrm{g}$ ) (Agusa et al., 2006).

\subsection{Comparison between villages, gender, age and residence status}

Significant and strong pairwise correlation $(r \geq 0.6, p<0.01)$ was found between $\mathrm{Cr}-\mathrm{Ni}, \mathrm{Cd}-\mathrm{Cu}, \mathrm{Cd}-\mathrm{Pb}, \mathrm{Cu}-\mathrm{Pb}$ (Table 2). The correlation matrix for pooled Ningbo and Shaoxing data revealed a different pattern, with significant pairwise correlations between $\mathrm{V}, \mathrm{Mn}$, As and $\mathrm{Pb}$, indicating background exposures through dietary and anthropogenic sources (Table S2). Lead was further moderately correlated with Cd $(r=0.56, p<0.05)$ but had no correlation with $\mathrm{Cu}$ in the control areas, giving further evidence for e-waste related exposure of $\mathrm{Pb}$ and $\mathrm{Cu}$ in TZ. Sub-ppm levels of $\mathrm{Cd}$ and low ppm levels of $\mathrm{Cu}$ and $\mathrm{Pb}$ were found in an exposed population in an industrialized region in Poland but no inter-correlations were found between these three metals (Chojnacka et al., 2005), and hair levels in school children in Istanbul were found to be around $53 \mathrm{ng} /$ $\mathrm{g}$ for $\mathrm{Cd}$ and $2.4 \mu \mathrm{g} / \mathrm{g}$ for $\mathrm{Pb}$ with moderate inter-correlation (Özden et al., 2007). Besides recycling e-waste, the Taizhou area also holds a large number of heavy industries such as those producing plastics, valves, water pumps and petrochemical products. Moderate correlation between several of the metals might, besides to e-waste activities, also be related to these other industries (Table 2).

Higher concentrations for males in regards to $\mathrm{Cd}$ and $\mathrm{Pb}$, and higher levels of $\mathrm{Cr}$ and $\mathrm{Ni}$ for females were observed $(p<0.05)$, which might be explained by gender specific differences and/or higher representation of males directly involved in e-waste recycling operations (Supplementary Material, Fig. S1). However, the sample size of female participants was too small $(n=9)$ to provide statistical power to the observations.

Among the villages in TZ, distinct differences were found for all elements except As, Mn and V ( $p<0.05$, one-way ANOVA, Fig. 1$)$. All of the study participants in Recycling Park (RP) were non-locals, which is in accordance with the common perception that the intensive recycling and manual salvaging labors in e-waste processing centers are mostly carried out by migrant workers (Hicks et al., 2005). Higher GMs were found in RP for Ba $(3.74 \mu \mathrm{g} / \mathrm{g}), \mathrm{Cd}$ $(0.803 \mu \mathrm{g} / \mathrm{g}), \mathrm{Cu}(53.6 \mu \mathrm{g} / \mathrm{g})$ and $\mathrm{Pb}(72.8 \mu \mathrm{g} / \mathrm{g})$ compared to the other villages, but due to the large variances, it was only statistically found for Cd against BFQ and BFA ( $p<0.05$, one-way ANOVA, Tukey's post hoc test). Anrong village had high GMs of $\mathrm{Cr}(2.32 \mu \mathrm{g} /$ $\mathrm{g})$, Mn $(6.70 \mu \mathrm{g} / \mathrm{g})$ and $\mathrm{Ni}(2.88 \mu \mathrm{g} / \mathrm{g})$, but was not significant compared to the other sites. Significantly higher levels of $\mathrm{Ba}, \mathrm{Cd}, \mathrm{Cu}$ and $\mathrm{Pb}$ were found for non-local residents, while higher median levels of $\mathrm{Cr}$, Ni, As were found for local residents ( $p<0.05$, Fig. 2$)$. If assumed that all non-locals are directly involved in e-waste

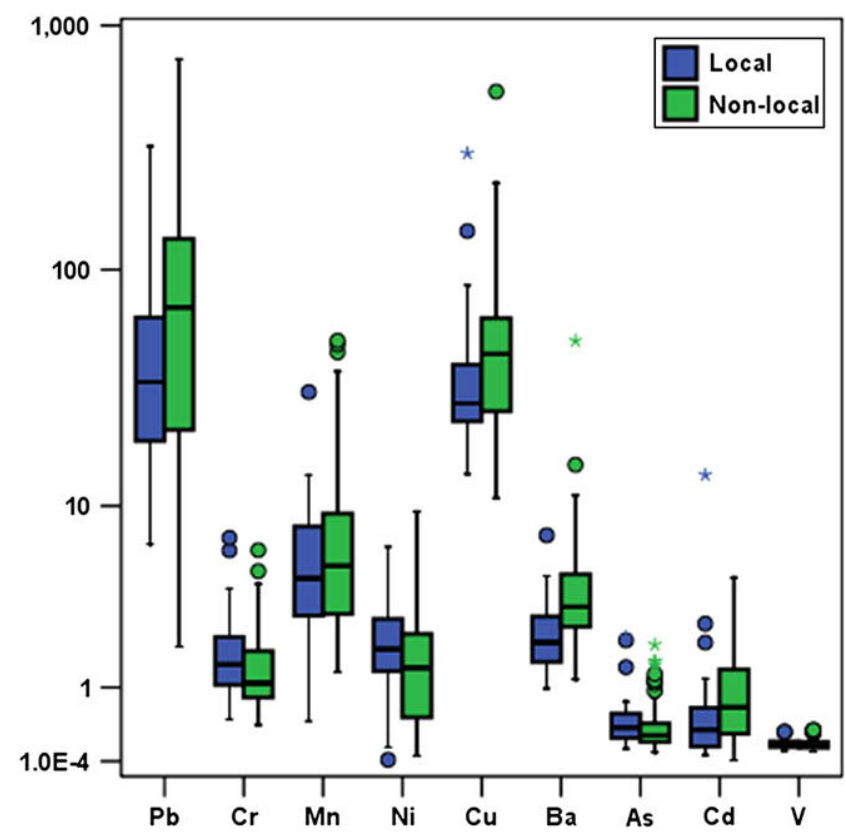

Fig. 2. Box-plot diagram of selected elements for subjects in TZ grouped by residence status: local resident $(n=42)$, non-local resident $(n=97)$.

dismantling processes, then plotting only data on non-locals against villages should more accurately reflect the direct occupational exposure between the villages (Fig. S2). The concentration profiles in Fig. S2 did not differ significantly to that observed in Fig. 1, with similar concentrations of $\mathrm{Cu}, \mathrm{Pb}$ and $\mathrm{Cd}$ in $\mathrm{RP}$ as other sites. This should confirm the widespread occurrence of e-waste activities in this area, and suggests that the establishment of a special recycling zone, although might reduce environmental discharges of e-waste pollutants, does not significantly help in reducing the occupational exposure of dismantling workers.

Very significant differences between age were found for $\mathrm{Ni}$ and $\mathrm{Cd}(p<0.01)$, both classified as potential carcinogens, and higher GMs of $\mathrm{Cr}(1.88 \mu \mathrm{g} / \mathrm{g})$ and $\mathrm{Ni}(3.00 \mu \mathrm{g} / \mathrm{g})$ found for the most vulnerable age group (children $<16$ years), (Fig. 3 ). The Pb levels of these children (GM: $29.6 \mu \mathrm{g} / \mathrm{g}$ ) were also much higher than those in the control subjects, supporting previous studies regarding elevated blood lead levels of children in e-waste recycling areas (Huo et al., 2007; Zheng et al., 2008). The subjects in the 26-55 age groups are more likely to be directly involved in e-waste recycling activities and correspondingly, the highest $\mathrm{GMs}$ of $\mathrm{Cd}, \mathrm{Cu}$ and $\mathrm{Pb}$ were also found in those groups compared to the younger and older groups. The trend for $\mathrm{Cd}$ is also similar with the perception that the highest body burdens of $\mathrm{Cd}$ are reached for adults and middle aged individuals and decreased thereafter (ATSDR, 2008).

Table 2

Pearson correlation matrix of log-transformed data set for Taizhou samples.

\begin{tabular}{|c|c|c|c|c|c|c|c|c|c|}
\hline & V & $\mathrm{Cr}$ & Mn & $\mathrm{Ni}$ & $\mathrm{Cu}$ & As & $\mathrm{Cd}$ & $\mathrm{Ba}$ & $\mathrm{Pb}$ \\
\hline$\overline{\mathrm{V}}$ & 1 & 0.124 & $0.302\left(^{* *}\right)$ & $0.183\left({ }^{*}\right)$ & $0.180\left(^{*}\right)$ & $0.322\left(^{* *}\right)$ & $0.243\left(^{* *}\right)$ & 0.159 & 0.155 \\
\hline $\mathrm{Cr}$ & 0.124 & 1 & $0.206\left(^{*}\right)$ & $0.617\left(^{* *}\right)$ & -0.081 & 0.019 & $-0.190\left(^{*}\right)$ & -0.071 & -0.067 \\
\hline Mn & $0.302\left(^{* *}\right)$ & $0.206\left(^{*}\right)$ & 1 & $0.351\left(^{* *}\right)$ & 0.055 & -0.036 & 0.129 & $0.281\left(^{* *}\right)$ & 0.093 \\
\hline $\mathrm{Ni}$ & $0.183\left(^{*}\right)$ & $0.617\left(^{* *}\right)$ & $\left.0.351{ }^{(* *}\right)$ & 1 & -0.096 & 0.067 & $-0.234\left({ }^{* *}\right)$ & -0.129 & $-0.204\left(^{*}\right)$ \\
\hline $\mathrm{Cu}$ & $0.180\left(^{*}\right)$ & -0.081 & 0.055 & -0.096 & 1 & -0.119 & $0.585\left(^{* *}\right)$ & $0.241\left(^{* *}\right)$ & $0.651\left(^{* *}\right)$ \\
\hline As & $0.322\left(^{* *}\right)$ & 0.019 & -0.036 & 0.067 & -0.119 & 1 & -0.061 & -0.040 & -0.105 \\
\hline $\mathrm{Cd}$ & $0.243\left(^{* *}\right)$ & $-0.190\left(^{*}\right)$ & 0.129 & $-0.234\left({ }^{* *}\right)$ & $0.585\left(^{* *}\right)$ & -0.061 & 1 & $0.271\left(^{* *}\right)$ & $0.702\left(^{* *}\right)$ \\
\hline $\mathrm{Ba}$ & 0.159 & -0.071 & $0.281\left(^{* *}\right)$ & -0.129 & $0.241\left(^{* *}\right)$ & -0.040 & $0.271\left(^{* *}\right)$ & 1 & $0.211\left(^{*}\right)$ \\
\hline $\mathrm{Pb}$ & 0.155 & -0.067 & 0.093 & $-0.204\left(^{*}\right)$ & $0.651\left(^{* *}\right)$ & -0.105 & $0.702\left(^{* *}\right)$ & $0.211\left(^{*}\right)$ & 1 \\
\hline
\end{tabular}

** Correlation is significant at the 0.01 level (2-tailed).

* Correlation is significant at the 0.05 level (2-tailed). 


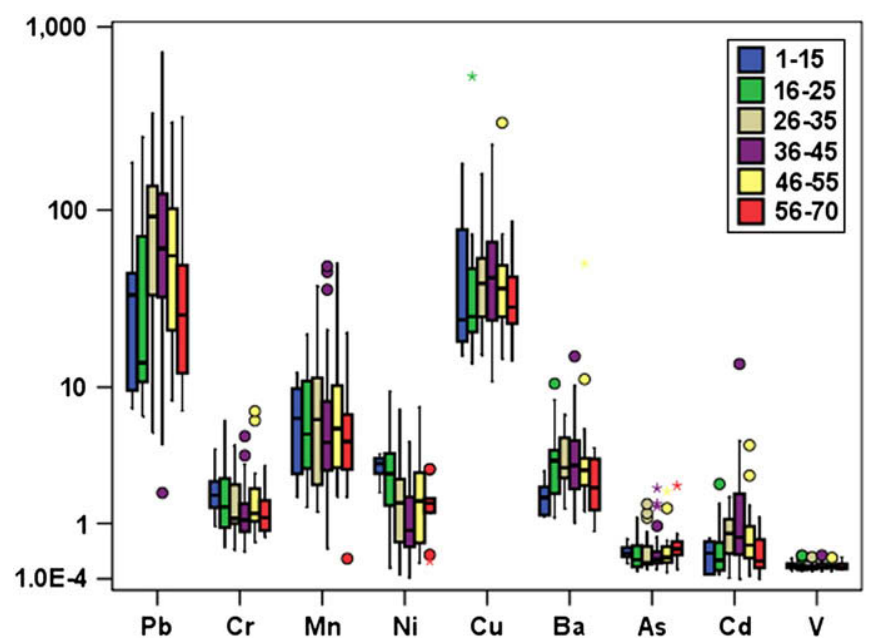

Fig. 3. Box-plot diagram of selected elements for the subjects in TZ grouped by age: 115 years $(n=6), 16-25(n=20), 26-35(n=22), 36-45(n=56), 46-55(n=25), 56-70$ $(n=10)$.

\subsection{Principal component analysis}

Principal component analysis (PCA) is often used to reduce multidimensional data set into a few linear combinations while preserving most of the original information, and has been widely used in environmental research to allocate the origin of contaminants. We investigated the possibility of using PCA to further study the inter-relationship between the hair element levels and discuss potential sources. Using PCA, three principal components (PCs), accounting for $76 \%$ of the total variances were extracted (Table S3). During the first iterations, Ba had low communality $(<0.5)$ and Mn showed complex structure (loading $>0.4$ on more than one component), and was therefore deemed not suitable for PCA and removed from the analysis. Factor 1 was strongly associated with $\mathrm{Pb}$ (correlation: 0.917), $\mathrm{Cu}(0.884)$ and $\mathrm{Cd}(0.856)$. Factor 2 was predominated by $\mathrm{Cr}(0.887)$ and $\mathrm{Ni}(0.884)$, whereas the third component had high loading of As (0.788) and V (0.826).

The scores and loadings for the components can be plotted with each case marked by subject location and residence status, to further visualize the relationships. For the first two components; $\mathrm{Cd}, \mathrm{Cu}$ and $\mathrm{Pb}$ were found at the first and fourth quadrant and those subjects located at the right hand side in the corresponding score plot should be associated with these three metals (Fig. 4a). The concentrations of those individuals also showed higher accumulation of these metals compared to the rest (Fig. S3). Those subjects on the upper side (I and II quadrant) of the origin are related with $\mathrm{Ni}$ and $\mathrm{Cr}$, where most reside in Baifeng'ao and Anrong village. Since Taizhou also specializes in processing transformers, one might expect $\mathrm{Ni}-\mathrm{Cr}$ based metal alloys, frequently used in heat and electrical resistant applications, to be released into the environment. The GMs of $\mathrm{Ni}(\sim 2.5 \mu \mathrm{g} / \mathrm{g})$ and $\mathrm{Cr}(\sim 2.0 \mu \mathrm{g} / \mathrm{g})$ for those in quadrant I and II were also significantly higher than those in the
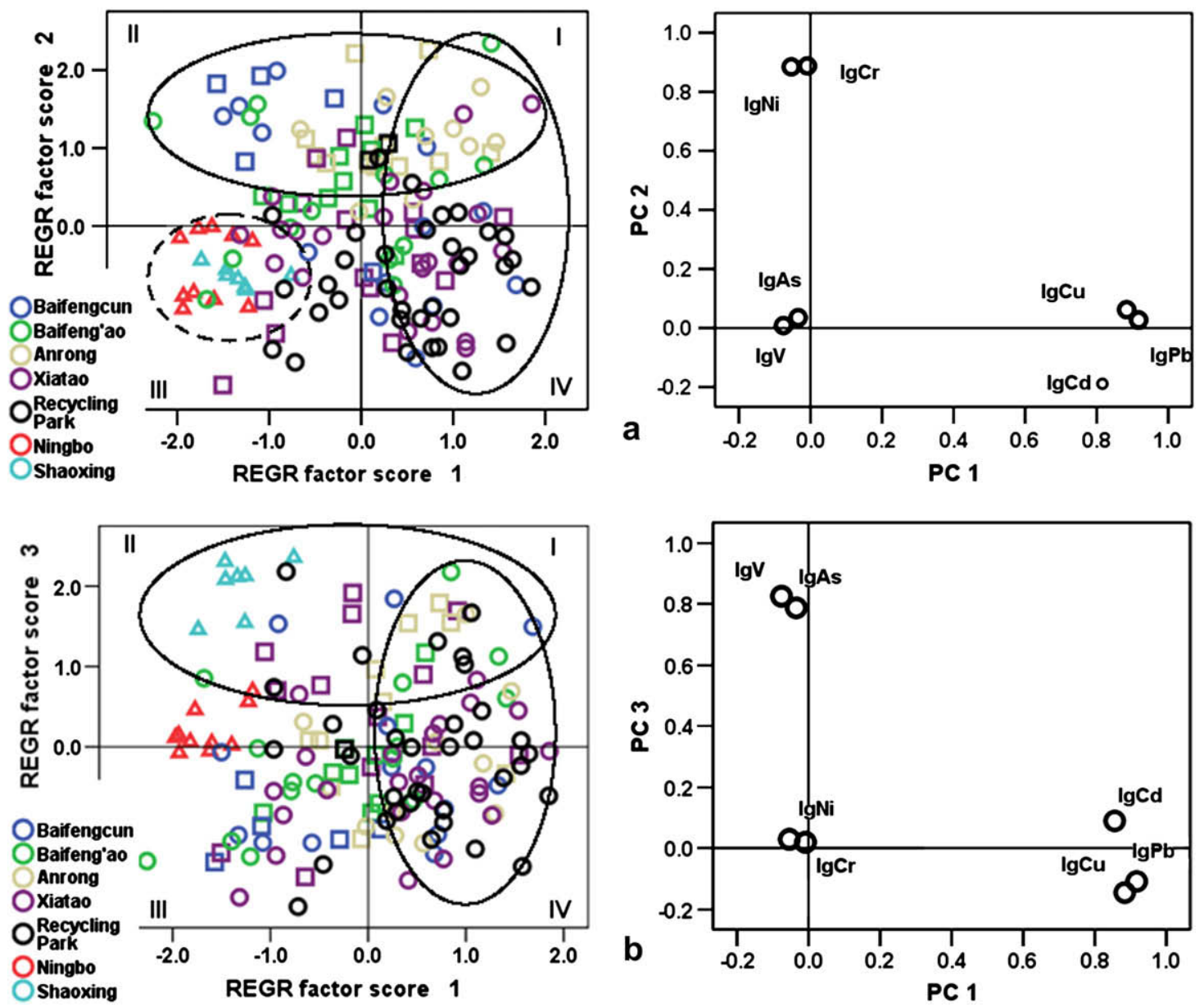

Fig. 4. Loading and score plots from PCA of log-transformed data set. Square symbols represent local resident, circles represent non-locals and triangles represent controls. 
control areas. Fu and co-workers (2008) also found that farm soil concentrations of $\mathrm{Cr}(\mathrm{GM}=61.2 \mu \mathrm{g} / \mathrm{g})$ and $\mathrm{Ni}(34.7 \mu \mathrm{g} / \mathrm{g})$ in $\mathrm{TZ}$ were higher than the corresponding background levels. Plotting PC1 against PC3 also shows similar patterns and with higher concentrations of As and $\mathrm{V}$ for those subjects in the first and second quadrant. As expected, samples from Shaoxing, having higher concentrations of these two elements (Fig. 1) were positioned at the second quadrant. Non-locals and those in RP were more represented at the right hand side of the origin, further validating the PCA.

\subsection{Reliability of multivariate analysis for source apportionment of hair trace elements}

Hair element analysis has been used for decades, but its reliability as a biomarker to assess environmental exposure of contaminants is still being widely discussed by the scientific community (Harkins and Susten, 2003). One of the main difficulties is the inability to completely separate endogenous elements from exogenous contamination, as a proportion of certain compounds from external sources is deemed to be incorporated and strongly bound to the hair structure, making it difficult to establish reference values of hair levels to indicate what levels might be detrimental to human health (Kempson et al., 2006). It is therefore difficult to interpret the health implications of the elevated hair levels of certain heavy metals observed in our study, especially as simple visual inspection on the outer appearances of the participants in TZ during collection did not imply severe health problems. However, other studies conducted in Guiyu found high incidences of ailments such as headaches, skin diseases, chronic gastritis and more (Qiu et al., 2004).

Source apportionment using human hair has not been rigorously tested for its suitability since it is a different medium than e.g. soil or air particulates. There have only been a few attempts to use multivariate analysis to identify sources of hair trace elements for general populations (Nowak and Chmielnicka, 2000; Chojnacka et al., 2005; Shah et al., 2006), although those did not discuss the rigidity and reliability of the methods used. Uptake mechanisms and pharmacokinetics might alter the concentration trends of elements in hair of each individual from what is observed in the surrounding environment, making source apportionment difficult. The results from the correlation and multivariate analyses in this study can therefore be interpreted in three ways; that exogenous sources dominate the observations, and thus reflect external environmental sources. Long-term occupational exposure would eventually lead to incorporation of exogenous contamination to the hair structure, which suggests that hair acts as a passive sampler for particulate and gaseous phase pollutants and should reflect ambient environmental/occupational conditions. A previous study found the same concentration profiles for $\mathrm{Cd}$ and $\mathrm{Pb}$ along the length of the scalp hair (Rodushkin and Axelsson, 2003), and while Morton et al. (2002) found through a 24 h simulated spiked sweat experiment that exogenous $\mathrm{Pb}$ should not be strongly bound to hair ( $94 \%$ of $\mathrm{Pb}$ could be removed during the washing step), another study by Kempson and co-workers (2006) found that Pb can be distributed in non-particulate form on the hair surface of an exposed lead smelter worker, and the exogenously originated $\mathrm{Pb}$ might be incorporated into the hair structure by time. The warm conditions in the workshops and the humid weather conditions in TZ should also promote more sweating which then can dissolve deposited exogenous elements, which easier becomes incorporated into the hair structure.

A second explanation would be that all exogenously deposited contamination has been removed by the washing step and thus the levels and observations mirror the uptake and exposure through inhalation and/or diet. Previous studies also contested that $\mathrm{Cu}$ levels in hair should not be significantly contributed by exogenous contamination and thus reflect endogenous pathways (Kempson et al., 2006). The third assumption would be a combination of both endogenous and exogenous processes and is probably the case for most observations in highly polluted environmental and occupational settings, such as those in our current study.

\section{Conclusions}

The results from our present study show that the use of hair as a noninvasive and cost-effective method can provide preliminary information on the exposure of heavy metals and toxic elements to residents and workers in areas that are heavily contaminated due to intensive e-waste recycling activities. Very high concentrations of $\mathrm{Cu}$ and $\mathrm{Pb}$ were found in hair of residents in e-waste recycling areas, compared to those in control sites and those of other studies on non-occupationally exposed populations. Through multivariate analysis, $\mathrm{Cd}, \mathrm{Pb}$ and $\mathrm{Cu}$ were found to be highly correlated and contamination from e-waste related activities is likely to be the source of origin for all three heavy metals in human scalp hair. This correlation pattern can be useful as marker of high exposure to heavy metals due to e-waste recycling activities. Further studies are recommended to evaluate the correlation between the elevated levels of contaminants in hair with blood/urine samples and adverse health effects, and to further allocate the different exposure pathways.

\section{Acknowledgment}

The authors are grateful for the assistance provided by Drs. Yongguang Yin, Guangshu Zhai and Honghua Li. This work was supported by National Science Foundation of China (20897010; 20621703) and National Basic Research Program of China (2009CB421600).

\section{Appendix. Supplementary material}

Supplementary data associated with this article can be found, in the online version, at doi:10.1016/j.envpol.2009.03.010.

\section{References}

Agusa, T., Kunito, T., Fujihara, J., Kubota, R., Minh, T.B., Trang, P.T.K., Iwata, H. Subramanian, A., Viet, P.H., Tanabe, S., 2006. Contamination by arsenic and other trace elements in tube-well water and its risk assessment to humans in Hanoi, Vietnam. Environ. Pollut. 139, 95-106.

Altshul, L., Covaci, A., Hauser, R., 2004. The relationship between levels of PCBs and pesticides in human hair and blood: preliminary results. Environ. Health Perspect. 112, 1193-1199.

ATSDR, 2008. Agency for Toxic Substances and Disease Registry. Toxicological Profile for Cadmium. US Department of Health and Human Services.

Basel Action Network, 2002. Exporting Harm: the High Tech Thrashing of Asia.

Chojnacka, K., Gorecka, H., Chojnacki, A., Gorecki, H., 2005. Inter-element interactions in human hair. Environ. Toxicol. Pharmacol. 20, 368-374.

Deng, W.J., Louie, P.K.K., Liu, W.K., Bi, X.H., Fu, J.M., Wong, M.H., 2006. Atmospheric levels and cytotoxicity of PAHs and heavy metals in TSP and PM2.5 at an electronic waste recycling site in southeast China. Atmos. Environ. 40, 69456955.

Fu, J.J., Zhou, Q.F., Liu, J.M., Liu, W., Wang, T., Zhang, Q.H., Jiang, G.B., 2008. High levels of heavy metals in rice (Oryza sativa L.) from a typical E-waste recycling area in southeast China and its potential risk to human health. Chemosphere 71 , 1269-1275.

Gullett, B.K., Linak, W.P., Touati, A., Wasson, S.J., Gatica, S., King, C.J., 2007. Characterization of air emissions and residual ash from open burning of electronic wastes during simulated rudimentary recycling operations. J. Mater. Cycles Waste Manag. 9, 69-79.

Harkins, D.K., Susten, A.S., 2003. Hair analysis: exploring the state of the science. Environ. Health Perspect. 111, 576-578. 
Hicks, C., Dietmar, R., Eugster, M., 2005. The recycling and disposal of electrical and electronic waste in China-legislative and market responses. Environ. Impact Asses. 25, 459-471.

Huo, X., Peng, L., Xu, X.J., Zheng, L.K., Qiu, B., Qi, Z.L., Zhang, B., Han, D., Piao, Z.X. 2007. Elevated blood lead levels of children in Guiyu, an electronic waste recycling town in China. Environ. Health Perspect. 115, 1113-1117.

Kempson, I.M., Skinner, W., Kirkbride, K.P., 2006. Advanced analysis of metal distributions in human hair. Environ. Sci. Technol. 40, 3423-3428.

Khuder, A., Bakir, M.A., Hasan, R., Mohammad, A., 2008. Determination of nickel copper, zinc and lead in human scalp hair in Syrian occupationally exposed workers by total reflection X-ray fluorescence. Environ. Monit. Assess. 143, 67-74.

Leung, A.O.W., Cai, Z.W., Wong, M.H., 2006. Environmental contamination from electronic waste recycling at Guiyu, southeast China. J. Mater. Cycles Waste Manag. 8, 21-33.

Leung, A.O.W., Luksemburg, W.J., Wong, A.S., Wong, M.H., 2007. Spatial distribution of polybrominated diphenyl ethers and polychlorinated dibenzo-p-dioxins and dibenzofurans in soil and combusted residue at Guiyu, an electronic waste recycling site in southeast China. Environ. Sci. Technol. 41, 2730-2737.

Leung, A.O.W., Duzgoren-Aydin, N.S., Cheung, K., Wong, M.H., 2008. Heavy metals concentrations of surface dust from e-waste recycling and its human health implications in Southeast China. Environ. Sci. Technol. 42, 2674-2680.

Li, J., Lu, H.Z., Guo, J., Xu, Z.M., Zhou, Y.H., 2007. Recycle technology for recovering resources and products from waste printed circuit boards. Environ. Sci. Technol. 41, 1995-2000.

Morton, J., Carolan, V.A., Gardin, P.H.E., 2002. Removal of exogenously bound elements from human hair by various washing procedures and determination by inductively coupled plasma mass spectrometry. Anal. Chim. Acta 455, 23-34.

Nowak, B., Chmielnicka, J., 2000. Relationship of lead and cadmium to essential elements in hair, teeth, and nails of environmentally exposed people. Ecotoxicol. Environ. Saf. 46, 265-274.

Özden, T.A., Gökçay, G., Ertem, H.V., Süoğlu, Ö.D., Kılıç, A., Sökücü, S., Saner, G., 2007. Elevated hair levels of cadmium and lead in school children exposed to smoking and in highways near schools. Clin. Biochem. 40, 52-56.

Pereira, R., Ribeiro, R., Goncalves, F., 2004. Scalp hair analysis as a tool in assessing human exposure to heavy metals (S. Domingos mine, Portugal). Sci. Tota Environ. 327, 81-92.

Qiu, B., Peng, L., Xu, X., Lin, X., Hong, J., Huo, X., 2004. Medical investigation of ewaste demanufacturing industry in Guiyu town. In: Proceedings of the
International Conference on Electronic Waste and Extended Producer Responsibility. Greenpeace and Chinese Society for Environmental Sciences, Beijing, pp. 79-83.

Rodrigues, J.L., Batista, B.L., Nunes, J.A., Passos, C.J.S., Barbosa, F.J., 2008. Evaluation of the use of human hair for biomonitoring the deficiency of essential and exposure to toxic elements. Sci. Total Environ. 405, 370-376.

Rodushkin, I., Axelsson, M.D., 2000. Application of double focusing sector field ICPMS for multielemental characterization of human hair and nails. Part II. A study of the inhabitants of northern Sweden. Sci. Total Environ. 262, 21-36.

Rodushkin, I., Axelsson, M.D., 2003. Application of double focusing sector field ICPMS for multielemental characterization of human hair and nails. Part III. Direct analysis by laser ablation. Sci. Total Environ. 305, 23-39.

Shah, M.H., Shaheen, N., Khalique, A., Alrabti, A.A.A., Jaffar, M., 2006. Comparative metal distribution in hair of Pakistani and Lybian population and source identification by multivariate analysis. Environ. Monit. Assess. 114, 505-519.

United Nations Environment Programme, 2005. E-waste, the Hidden Side of IT Equipment's Manufacturing and Use.

Wen, S., Yang, F.X., Gong, Y., Zhang, X.L., Hui, Y., Li, J.G., Liu, A.L., Wu, Y.N., Lu, W.Q., $\mathrm{Xu}, \mathrm{Y} ., 2$ 2008. Elevated levels of urinary 8-hydroxy-2'-deoxyguanosine in male electrical and electronic equipment dismantling workers exposed to high concentrations of polychlorinated dibenzo-p-dioxins and dibenzofurans, polybrominated diphenyl ethers, and polychlorinated biphenyls. Environ. Sci. Technol. 42, 4202-4207.

Wolfsperger, M., Hauser, G., Goessler, W., Schlagenhaufen, C., 1994. Heavy metals in human hair samples from Austria and Italy: influence of sex and smoking habits. Sci. Total Environ. 156, 235-242.

Wong, C.S.C., Duzgoren-Aydin, N.S., Aydin, A., Wong, M.H., 2007a. Evidence of excessive releases of metals from primitive e-waste processing in Guiyu, China. Environ. Pollut. 148, 62-72.

Wong, C.S.C., Wu, S.C., Duzgoren-Aydin, N.S., Aydin, A., Wong, M.H., 2007b. Trace metal contamination of sediments in an e-waste processing village in China. Environ. Pollut. 145, 434-442.

Zhao, G.F., Wang, Z.J., Dong, M.H., Rao, K.F., Luo, J.P., Wang, D.H., Zha, J.M., Huang, S.B., Xu, Y.P., Ma, M., 2008. PBBs, PBDEs, and PCBs levels in hair of residents around e-waste disassembly sites in Zhejiang Province, China, and their potential sources. Sci. Total Environ. 397, 46-57.

Zheng, L.K., Wu, K.S., Li, Y., Qi, Z.L., Han, D., Zhang, B., Gu, C.W., Chen, G.J., Liu, J.X. Chen, S.J., Huo, X., 2008. Blood lead and cadmium levels and relevant factors among children from an e-waste recycling town in China. Environ. Res. 108, 15-20. 